\title{
Gestão Participativa em Unidades de Conservação com ênfase nos instrumentos legais: um olhar a partir da RDS Estadual Ponta do Tubarão (RN)
}

\section{Participatory Management in protected areas with emphasis on legal instruments: a view from the RDS State Ponta do Tubarão (RN, Brazil)}

Iracy Wanderley-Filha, Maria Valéria Pereira de Araújo, Sonia Trigueiro de Almeida

\begin{abstract}
RESUMO
As unidades de conservação são espaços naturais em que se observa a presença de pessoas cuja existência se baseia em sistemas sustentáveis de exploração dos recursos ecológicos, desenvolvidos por diversas gerações, adaptados às condições naturais locais e que desempenham um papel básico na proteção da natureza e na manutenção da diversidade biológica. O artigo objetiva identificar e compreender a compatibilização entre as previsões da Lei Federal no 9.985 que criou o Sistema Nacional de Unidades de Conservação - SNUC, da Lei Complementar no 272/04 e da Lei Estadual $n \cong 8.349 / 03$ que cria a Reserva de Desenvolvimento Sustentável Estadual Ponta do Tubarão, no que diz respeito a aplicabilidade dos princípios constitucionais de garantia do direito de participação social na gestão de Unidades de Conservação - UCs, na gestão ambiental da reserva. A referida reserva abrange os limites dos municípios de Macau e Guamaré, no Estado do Rio Grande do Norte. Trata-se de uma pesquisa bibliográfica e documental de natureza exploratória e de caráter qualitativo. Os resultados mostraram que apresenta certa acuidade no tocante ao alinhamento legal que cria e implementa a RDS com Lei Complementar 272/04 e às previsões da Lei 9.985/00 clareando e garantindo as formas de participação na gestão da unidade pelo Conselho Gestor com vistas ao desenvolvimento comunitário local.
\end{abstract}

PALAVRAS-CHAVE: Gestão Participativa; Unidade de Conservação; Instrumentos Legais. 


\section{ABSTRACT \\ Protected areas are natural areas where there is the presence of people whose existence is based on sustainable farming systems of ecological resources, developed by several generations, adapted to local natural conditions and play a basic role in protecting nature and maintenance of biological diversity. The article aims to identify and understand the compatibility between the predictions of Federal Law 9985 that created the National Protected Areas System - SNUC, of Complementary Law 272/04 and the State Law 8.349/03 establishing a Development Reserve Sustainable State Ponta do Tubarão, with regard to applicability of constitutional principles guaranteeing the right of social participation in protected areas management - UCs, environmental management reserve. Said reserve covers the limits of Macau and Guamaré municipalities in the state of Rio Grande do Norte. It is a bibliographical and documentary research exploratory and qualitative. The results showed that presents a certain accuracy regarding the legal alignment that creates and implements the RDS with Complementary Law 272/04 and forecasts of Law 9.985/00 clearing and securing the forms of participation in the management of the unit by the Management Board with a view to developing local community.}

KEYWORDS: Participative Management; Conservation Unit; Legal instruments.

\section{Introdução}

O modelo de gestão pública brasileiro, até o final da década de setenta, ainda concentrava suas decisões no nível do Governo Federal, ficando as competências residuais atribuídas aos estados e, para os municípios, as atribuições de interesse local.

Este processo se transforma significativamente, a partir dos anos oitenta, a partir da crise do modelo existente e das mudanças no desempenho político-institucional (JACOBI,1999).

Essa constatação também influencia a dimensão ambiental do Brasil que está passando de um imperativo preservacionista, com sua execução centralizada no nível governamental, para um processo que requer maior participação popular. Esse processo decorre da tendência de segmentos sociais buscarem a conciliação entre preservação ambiental e promoção do desenvolvimento local podendo resultar num avanço significativo para 0 cenário ambiental brasileiro.

No que concerne aos instrumentos formais que garantem a participação social no cenário brasileiro, pode-se citar a Constituição Federal (CF) de 1988 que em seu art. 225 reconhece a necessidade da participação social na gestão ambiental.

Pelo que se constata, a participação social na gestão do meio ambiente é um processo de conquista em andamento, que vem se configurando no cenário das arenas de discussões da sociedade brasileira. Em virtude disso, esse tema vem recebendo destaques como os clarificados na concepção de Bordaneve (1994, p.74), cujo autor afirma ser a 
participação uma vivência coletiva e não individual, de modo que somente se pode aprender na práxis grupal.

Numa Unidade de Conservação (UC) ${ }^{1}$, o processo de participação social é garantido pela lei no 9.985/2000 que instituiu o Sistema Nacional de Unidades de Conservação da Natureza - SNUC, regulamentou o artigo 225 da CF e orientou os critérios para a criação, implantação e gestão das UCs. O SNUC estabelece os grupos de unidades de Proteção Integral, cujo objetivo é preservar a natureza, sendo admitido apenas o uso indireto dos seus recursos naturais, com exceção dos casos previstos nesta Lei. Os de Uso Sustentável objetivam compatibilizar a conservação da natureza com o uso sustentável de parcela dos seus recursos naturais (BRASIL, 2000)

Esses grupos foram subdivididos em 12 (doze) categorias específicas classificadas em função do capital natural a ser protegido: Estação Ecológica, Parque Nacional, Reserva Biológica, Monumento Natural e Refúgio da Vida Silvestre (Proteção Integral). No grupo Uso Sustentável encontra-se as categorias Área de Proteção Integral, Área de Relevante Interesse Ecológico, Floresta Nacional, Reserva Extrativista, Reserva de Fauna, Reserva de Desenvolvimento Sustentável e Reserva Particular do Patrimônio Natural (BRASIL, 2000).

Cerne das discussões traçadas neste trabalho o SNUC, define a Reserva de Desenvolvimento Sustentável (RDS) como espaços naturais em que se observa a presença de pessoas cuja existência se baseia em sistemas sustentáveis de exploração dos recursos ecológicos, desenvolvidos por diversas gerações, adaptados às condições naturais locais e que desempenham um papel básico na proteção da natureza e na manutenção da diversidade biológica (BRASIL, 2000)

A RDS Estadual Ponta do Tubarão (RDSEPT), localizada no Rio Grande do Norte (RN) foi instituída em 17 de julho de 2003, por meio da lei estadual $n \cong$ 8.349. A RDSEPT abriga uma população de pescadores e agricultores e caracteriza-se por um sistema ecológico composto de ecossistema dunar e manguezal, adjacentes ao estuário do Rio Tubarão, área marinha e um espaço representativo do bioma caatinga, essa RDS foi a primeira unidade de conservação - UC estadual criada no Estado do Rio Grande do Norte e a segunda RDS estabelecida no Brasil.

De acordo com o Sistema Nacional de Unidades de Conservação da Natureza - SNUC, as instâncias de governança do poder público (federal, estadual e municipal) juntamente com representações sociais são responsáveis pelo processo de criação, implantação das unidades e fazem a gestão destas por meio do Conselho Gestor (CG) ${ }^{2}$, assegurando o que preconiza a Constituição Brasileira de 1988, no que se refere ao conceito de bem de uso comum do povo e essencial à qualidade de vida saudável.

Instrumentos como a Lei Federal no 9.985, a Lei Complementar no 272/04 que cria o Sistema Estadual de Unidades de Conservação - SEUC, no Rio Grande do Norte (RN) e a Lei Estadual no 8.349/03 apresenta diretrizes sobre a gestão, a composição e participação das entidades civis representantes no Conselho Gestor da Reserva de Desenvolvimento Sustentável Estadual Ponta do Tubarão - RDSEPT, garantem a participação popular e apresentam as diretrizes e estratégias para a efetividade da 
gestão participativa evidenciando o respeito à cultura local, o gerenciamento de possíveis conflitos resultantes da criação desta área protegida e a equidade na distribuição dos benefícios advindos da criação e gestão desta reserva.

Partindo-se da suposição preliminar de que na Reserva de Desenvolvimento Sustentável Estadual Ponta do Tubarão - RDSEPT existe um Conselho Gestor consolidado e paritário como também um Plano de Manejo (PM) ${ }^{3}$, este estudo tem o objetivo de relatar os processos de participação popular, na gestão ambiental da Reserva com ênfase nas previsões legais do Sistema Nacional de Unidades de Conservação da Natureza - SNUC.

Estudos dessa natureza auxiliam a construção de políticas públicas ambientais no sentido de expressarem a realidade das comunidades pertencentes às Unidades de Conservação e contribuírem com 0 desenvolvimento local e regional com vistas a sustentabilidade.

O presente estudo compreende uma pesquisa de natureza exploratória, adotando-se a coleta de dados secundários para 0 desenvolvimento da pesquisa bibliográfica e documental. Assim, foi realizada uma análise de conteúdo dos marcos regulatórios utilizados na criação e gestão da reserva, compreendendo a Lei Federal no 9.985/00, que instituiu o Sistema Nacional de Unidades de Conservação da Natureza SNUC; a Lei Complementar no 272/04 e a Lei Estadual $n$ ㅇ 8.349/03, que cria a Reserva de Desenvolvimento Sustentável Estadual Ponta do Tubarão. A categoria de análise, definida a priori, que norteou a análise de conteúdo para buscar palavras similares nos documentos foi à aplicabilidade dos princípios constitucionais de garantia do direito de participação social na gestão de UCs.

\section{Gestão participativa em Unidades de Conservação: uma abordagem conceitual e legal}

Participação é uma palavra latina cuja origem remonta ao século XV, que vem de participatio, participacionis, participatum. Representa o "tomar parte em", compartilhar, associar-se pelo sentimento ou pensamento. Além disso, sendo entendida de forma sucinta como a ação de indivíduos e grupos com o objetivo de influenciar o processo político. Representa ainda, com uma visão generalista como a ação que se desenvolve em solidariedade com outros no âmbito do estado ou de uma classe, com o objetivo de modificar ou conservar a estrutura (e portanto, os valores) de um sistema de interesses dominantes (AVELAR, 2004).

A partir da década de 80 , a sociedade brasileira conquista seu espaço participativo na formação do Estado democrático, superando as coerções do regime ditatorial impostas pelo golpe militar de 64. Nesse sentido, a participação da sociedade civil na tomada de decisões, no planejamento, na execução, no monitoramento e na avaliação de políticas, programas e projetos de interesse coletivo foi resultado de uma conquista político-social. Por esse motivo, a participação não é um processo que se encerra por si mesma, ela deve ser uma conquista contínua de caráter 
permanente. A evolução da participação da sociedade civil no processo de gestão acontece em seu cotidiano, na construção do processo histórico, político, ambiental, produtivo, cultural enfim, em tudo que diz respeito ao controle social sobre o processo de gestão. Tecendo reflexões acerca dos sentidos de participação social, Bordenave (1994, p.25) diz que "uma sociedade participativa seria, então, aquela em que todos os cidadãos têm parte na produção, gerência e usufruto dos bens da sociedade de maneira equitativa".

As definições e sentidos dados à participação são variados e isso se faz notar nas contribuições de LOUREIRO, 2005 apud Bezerra (2010, p. 32) que, nos seus estudos, definem a participação como um processo social que gera a interação entre diferentes atores sociais na definição do espaço comum e do destino coletivo. Nessas interações ocorrem relações que incidem e se manifestam em níveis distintos em função dos interesses, valores e percepções dos envolvidos. Nesse processo há uma relação com a cidadania, o protagonismo comunitário, o sentido de responsabilidade e de pertencimento a um grupo, classe ou comunidade. Igualmente, isso também pode ser percebido nas contribuições dos autores:

Participação é conquista para significar que é um processo, no sentido legítimo do termo: infindável, em constante vir a ser, sempre se fazendo. Assim, participação é em essência autopromoção e existe enquanto conquista processual. Não existe participação suficiente, nem acabada. (DEMO, 2001, p.18)

A participação da sociedade no exercício do poder político é o que oportuniza a prática da democracia, entendida esta como a liberdade de exercício dos direitos civis e políticos dos cidadãos, vistos estes dentro da ótica jusnaturalista (COGO; DALLABRIDA, 2013, p.3)

Loureiro (2003) pondera que as diversas "concepções de participação" podem ser agrupadas em três grandes vertentes: (1) liberal participação como movimento espontâneo de indivíduos, vistos como iguais; ela é inerente do espírito humano, não sendo determinada pelos interesses derivados do posicionamento dos atores sociais na sociedade; (2) revolucionária - participação como um processo de organização popular na luta contra as relações de dominação; e (3) democrática radical - entendida no sentido do fortalecimento da sociedade civil, em busca de uma nova ordem social.

De acordo com Sachs (1986), os principais indicadores de participação são: o poder de iniciativa conquistado pela comunidade; os espaços disponíveis para experiências reais, no nível local; o grau de simetria nas relações da sociedade civil com os diferentes níveis de governo e as forças de mercado; os mecanismos existentes para acordos e 
resolução de conflitos e, finalmente; a natureza do processo de planejamento.

Para facilitar a compreensão acerca da participação social na gestão de unidades de conservação se faz necessária a compreensão de alguns aspectos referentes à gestão e ao processo de participação social. $\mathrm{O}$ entendimento dos processos de participação da sociedade civil e sua presença na construção e execução de políticas públicas ${ }^{4}$ têm íntima relação com a concepção de democratização na sociedade brasileira e de suas lutas por acesso à cidadania e direitos sociais (GOHN, 2007 apud BEZERRA, 2010, p.31).

A importância da participação coletiva e consciente daqueles que compõem uma unidade social, tem a ver com a vontade de participar, causada por diversos fatores que vão desde a insatisfação política até a certeza de que a participação comunitária plena pode construir as bases para o empoderamento. É possível afirmar que isso acontece quando todos os envolvidos tomam consciência de seu poder de influência, no âmbito ao qual estão inseridos, e, assumem a responsabilidade de exercê-lo de forma dinâmica nas questões que surgirem e que Ihes são atribuídas.

A gestão participativa é comumente definida pelo compartilhamento de poderes e responsabilidades entre os diferentes atores, sendo os principais o governo e a comunidades locais. $O$ conceito é frequentemente igualado aos de gestão compartilhada, colaborativa, conjunta ou co-gestão (CARLSSON; BERKES, 2003).

Como explica MAGALHÃES et al., (2010, p.189) "a gestão participativa corresponde a um conjunto de princípios e processos que defendem e permitem o envolvimento regular e significativo dos colaboradores na tomada de decisão". Sendo assim, a participação efetiva e competente dos indivíduos, na dimensão da coletividade, se fortalece na resolução de problemas, possibilitando fazer intervenções participativas e garantindo resultados positivos.

Desse modo, a gestão participativa pode ser vista como uma condição básica para que se tenha eficiência e eficácia na gestão coletiva de políticas públicas. Porém, isso só se concretiza com uma cultura democrática por meio da participação social qualificada que se traduz num conjunto de atitudes, procedimentos e mecanismos que permitem sensibilizar, informar, tomar decisões conjuntas, exercer o controle social e permitir a participação igualitária.

Essa cultura [democrática] surge como um processo de identificação comunitária, em que a comunidade sente vontade de combater intervenções negativas e participar das decisões que afetam sua vida, somente reconhecendo como seu aquele projeto que, mesmo tendo vindo de fora, é capaz

No contexto ambiental brasileiro, a abordagem legal acerca da democratização da participação é garantida pela Constituição Federal de 1988 que abriu espaços à participação social na preservação e defesa 
ambiental. A CF, artigo 225, caput, CF/88 impôs à coletividade o dever de defender o meio ambiente e entendeu que "meio ambiente" é um bem de uso comum do povo. Nas Unidades de Conservação, a participação social é consagrada quando a Lei 9.985/2000 juramenta no Sistema Nacional de Unidades de Conservação a formulação de diretrizes que garantam às populações tradicionais ${ }^{5}$ como sendo aquela população que existe numa área antes da criação da UC desde, pelo menos, os seus pais, sendo que a tradição exigiria a prova dos ascendentes ligados à área ou nela presentes. Para fundamentar ainda mais a presunção legal, o artigo 23 , $\S 1$ 음 do SNUC institui que "as populações tradicionais das reservas extrativistas e das reservas de desenvolvimento sustentável estão obrigadas a participar da preservação, da recuperação, da defesa e da manutenção dessas unidades".

Desta forma, em seu Art. 5ํ o SNUC trata a participação social na gestão de Unidades de Conservação por diretrizes que: salvaguardam o patrimônio biológico existente; assegurem os mecanismos e procedimentos necessários ao envolvimento da sociedade no estabelecimento e na revisão da política nacional de unidades de conservação; permitam a participação efetiva das populações locais; busquem o apoio e a cooperação de organizações; assegurem a sustentabilidade econômica das unidades de conservação; permitam a conservação de populações das variantes genéticas selvagens dos animais e plantas domesticados e recursos genéticos silvestres; considerem as condições e necessidades das populações locais no desenvolvimento e adaptação de métodos e técnicas de uso sustentável dos recursos naturais; garantam uma alocação adequada dos recursos financeiros necessários para que, possam ser geridas de forma eficaz e atender aos seus objetivos; busquem conferir às unidades de conservação, autonomia administrativa e financeira; e busquem proteger os recursos naturais e restauração e recuperação dos ecossistemas (BRASIL, 2000).

Os incisos do artigo $5^{\circ}$ do SNUC estimulam e asseguram 0 envolvimento e o comprometimento dos indivíduos, das instituições públicas e privadas, e das organizações sociais na produção, gerência e usufruto dos bens naturais e sociais das unidades, de maneira equitativa. $\mathrm{O}$ inciso III da supracitada Lei, declara nitidamente a obrigatoriedade de se garantir a participação efetiva da população local na criação, implantação e gestão das unidades de conservação. A Lei $n^{\circ} 9.9985 / 00$, cita o termo "populações tradicionais" em diversas partes de seu texto e, apesar de em seu art. $2^{\circ}$, trazer definições de alguns termos necessárias ao seu entendimento, ainda não definiu a expressão "populações tradicionais" que é de grande importância para a implantação do Sistema Nacional de Unidades de Conservação. Isso também ocorre no Decreto n. 4.340/2002, que regulamentou alguns artigos do SNUC (CATTO, 2006, p.103). Ciente da importância dessa definição para o entendimento das questões discutidas nesse estudo, adota-se aqui a definição desta classificação populacional dada por Arruda (1997; p. 274 apud Diegues (2000) quando afirma que populações classificadas como tradicionais: 
[...] apresentam um modelo de ocupação do espaço e uso dos recursos naturais voltado principalmente para a subsistência, com fraca articulação com o mercado, baseado em uso intensivo de mão-de-obra familiar, tecnologias de baixo impacto derivadas de conhecimentos patrimoniais e, habitualmente, de base sustentável. Essas populações - caiçaras, ribeirinhos, seringueiros, quilombolas e outras variantes - em geral ocupam a região há muito tempo, não têm registro legal da propriedade privada individual, sendo o restante do território encarado como área de uso comunitário, com seu uso regulamentado pelo costume e por normas compartilhadas internamente.

No contexto da participação social é importante a definição desta classificação populacional, já que estas, dentre outros, têm o direito de tomar decisões que afetam diretamente o processo de criação, implantação e gestão dessas unidades de conservação. No tocante a reserva do desenvolvimento sustentável, o artigo $20, \S 1^{\circ}$ da mesma Lei dispõe que esta categoria de UC tem como objetivo básico preservar a natureza e, ao mesmo tempo, assegurar as condições e os meios necessários para a reprodução e a melhoria dos modos e da qualidade de vida e exploração dos recursos naturais das populações tradicionais, bem como valorizar, conservar e aperfeiçoar o conhecimento e as técnicas de manejo do ambiente, desenvolvido por estas populações. De acordo com esta normativa, a essas populações humanas é atribuído um papel de importância e visibilidade na preservação natureza e da cultura local como também na discussão dos problemas e soluções pertinentes à realidade socioambiental dessas áreas.

É importante ressaltar que a gestão participativa não é um estado fixado, mas um processo contínuo de resolução de problemas, envolvendo extensiva deliberação, negociação e aprendizagem conjunta (CARLSSON \& BERKES, 2003).

Para isso, é de suma importância que haja uma aproximação sinérgica entre os saberes representados por essas populações e os métodos e conhecimentos técnico-científico-informacionais. Addor (2007) apud Bezerra (2010, p. 33), frisam o seguinte:

[...] deve-se destacar que quando se procura desenvolver políticas públicas e realizar projetos de desenvolvimento local com cidadania, com o realce cultural, depara-se com o desafio de criar espaços de interação entre os diversos atores locais, na discussão dos problemas e construção das políticas públicas. Faz-se necessário utilizar métodos que possibilitem uma troca democrática e profícua. Urge, portanto, o aprofundamento no campo da metodologia participativa que possibilite a articulação dos atores e o diálogo entre conhecimento técnico-científico e o saber popular. 
O artigo 6ำ do SNUC prevê a gestão das unidades de conservação por meio de um arranjo institucional com as respectivas atribuições: Órgão consultivo e deliberativo: representado pelo Conselho Nacional do Meio Ambiente (CONAMA), tem a função de acompanhara implementação do SNUC; Órgão central: representado pelo Ministério do Meio Ambiente,tem a finalidade de coordenar o SNUC; Órgãos executores: representados na esfera federal, pelo Instituto Chico Mendes de Conservação da Biodiversidade (ICMBio) e IBAMA (Instituto Brasileiro do Meio Ambiente e dos Recursos), em caráter supletivo, e nas esferas estadual e municipal, pelos órgãos estaduais e municipais de meio ambiente. Ainda de acordo com o mecanismo legal em tela, os órgãos executores do SNUC têm a função de implementá-lo, subsidiar as propostas de criação e administrar as unidades de conservação federais, estaduais e municipais mas, nas respectivas esferas de atuação (Brasil, 2000). As competências dos órgãos para a gestão do Sistema vão desde a coordenação e o acompanhamento até a sua implementação propriamente dita.

Ainda referente à importância da gestão participativa, o SNUC e o seu decreto regulamentar, $n^{\circ}$ 4.340/02 prescrevem, em seus dispositivos, que cada UC deve dispor de um conselho gestor paritário, o qual visa, por essência, pautar as opiniões de setores presentes no espaço. Os processos participativos possibilitam, nas UCs, a permanência de espécies animais e vegetais nessas áreas protegidas e a preservação dos valores culturais sistemicamente inseridos nesse contexto, resultando num ganho para 0 meio socioambiental.

\section{A Gestão Participativa na RDSEPT: Relações entre o SNUC e os Instrumentos Normativos Locais}

O Sistema Nacional de Unidades de Conservação é a referência normativa que baliza as previsões de leis estaduais e municipais para criação, implantação e gestão de unidades de conservação brasileiras. Como explicitado no início, esse estudo aborda especificamente sobre os marcos legais e experiências de gestão participativa na RDS Estadual Ponta do Tubarão/RN, de modo que se possa identificar e compreender a compatibilização entre as previsões do SNUC, da Lei Complementar no 272/04 e da Lei Estadual $n \cong$ 8.349/03 (cria a Reserva de Desenvolvimento Sustentável Estadual Ponta do Tubarão), no que diz respeito à aplicabilidade dos princípios constitucionais de garantia do direito de participação social na gestão de unidades de conservação.

O objetivo básico das unidades de conservação de uso sustentado é compatibilizar a conservação da natureza com o uso de parcela de seus recursos naturais (SNUC, 2000). A legislação ambiental brasileira aponta como instrumentos de gestão nessas áreas protegidas, o plano de manejo, a zona de amortecimento, a educação ambiental e o conselho gestor. Esses são determinados por normas legais (Leis, Decretos, Resoluções, Instruções Normativas).

Conforme determina o artigo $5^{\circ}$ inciso $\mathrm{III}$, o SNUC é regido por diretrizes que "assegurem a participação efetiva das populações locais na 
criação, implantação e gestão das unidades de conservação". Esses processos de participação ocorrem formalmente através de três instrumentos: as Consultas Públicas, os Planos de Manejo e os Conselhos Gestores (MACEDO, 2007).

Pelo que rege a legislação ambiental brasileira, a gestão ambiental é de competência comum às instâncias de governança federal, estadual e municipal. Em seus dispositivos, o SNUC autoriza a participação de todos os cidadãos, residentes nessas áreas ou no entorno das unidades de conservação, interessados na sua gestão e garante maior transparência e fiscalização desse processo pelo envolvimento e comprometimento da sociedade civil.

No estado do Rio Grande do Norte a Lei Complementar № 272, de 3 de março de 2004, dispõe dentre outras, sobre a Política e o Sistema Estadual do Meio Ambiente e as unidades estaduais de conservação da natureza. O artigo 5o desta Lei Complementar define UC como espaço territorial e seus recursos ambientais, incluindo as águas jurisdicionais, com características naturais relevantes, legalmente instituídos pelo Poder Público, com objetivos de conservação e limites definidos, sob regime especial de administração, ao qual se aplicam garantias adequadas de proteção. Já o artigo 11 desta mesma Lei aponta o Sistema Estadual de Unidades de Conservação da Natureza (SEUC) como um dos instrumentos da Política Estadual do Meio Ambiente. Assim como prevê a Lei 9.985/00 a Lei 272/04, em seu artigo 19, também divide as UCs estaduais em grupos de uso sustentável e de uso integral com as mesmas conceituações dadas a esses termos pela primeira normativa. Mesmo assim, a Lei 272/04 não explicita sobre as categorias de UCs, podendo-se crer que estas podem ser as mesmas adotadas pelo SNUC já que a referida Lei, no $\S 1^{\circ}$ do artigo em tela, declara que serão aplicados os mesmos termos conceituais do SNUC para as unidades.

O artigo 19 da Lei da Política Ambiental do RN, também estabelece que à Entidade Executora integrante do Sistema Estadual de Meio Ambiente (SISEMA), nesse caso o Instituto de Desenvolvimento Sustentável e Meio Ambiente (Idema), cumpre a elaboração de propostas de intenção para criação, implantação e manutenção de unidades estaduais de conservação da natureza, precedidas de estudos técnicos e consulta pública. Essa instrução legal está em acordo com o que rege o SNUC, em seu artigo 22, onde admite ser a criação de unidades de conservação é por ato do Poder Público.

No contexto da gestão de unidades de conservação, o Art. 20, da Lei Complementar 272/04 deixa claro, apenas, que as UCs estaduais podem ser geridas por organizações da sociedade civil de interesse público com objetivos afins aos da unidade, mediante instrumento a ser firmado com o órgão responsável por sua gestão, devidamente precedido de licitação pública. Entende-se por essa disposição que essa organização social poderá, mediante processo de licitação concedido pelo órgão público integrante do SISEMA, gerir os interesses ambientais, sociais, econômicos, culturais, legalmente instituídos pelo objeto desta Lei. 
Como a RDS Estadual Ponta do Tubarão é o foco do objeto desse trabalho é lícito frisar que esta UC foi criada pelo Idema, por meio da Lei Estadual $n \cong 8.349 / 03$ obedecendo ao previsto no art. 22 do SNUC. Contudo, é importante destacar que a RDSEPT está situada nos municípios de Guamaré e Macau, região setentrional do Estado do Rio Grande do Norte, compreendendo as seguintes populações tradicionais: Barreiras, Diogo Lopes e Sertãozinho pertencentes ao município de Macau e Mangue Seco I e II e Lagoa Doce que fazem parte do município de Guamaré. Nesse espaço há um bioma costeiro, formado por um mosaico de ecossistemas encontrados ao longo do litoral composto por mar, manguezais, dunas, restingas, praias e lagoas. Há também a presença do bioma caatinga conferindo a essa área uma característica ecológica peculiar de encontro entre o semiárido e o litoral tendo os manguezais fazendo o limite entre esses biomas (IDEMA/RN, 2007).

Outras unidades geoambientais como tabuleiro, campo dunar com dunas fixas e dunas móveis, manguezal, zona de praia, planície de maré/estuarina e o oceano da plataforma continental podem ser encontradas nesse espaço. A pesca artesanal é uma das atividades de maior influência nessa região, caracterizando-se como a principal fonte de renda de boa parte da população, como um fator de importante agregação populacional e traduz a ideia de população tradicionalmente pesqueira (OLIVEIRA, 2008, p. 44 a 47).

O autor ainda destaca que a criação desta RDS foi fruto de uma mobilização da comunidade local preocupada com as ameaças predatórias provenientes da especulação imobiliária e da carcinicultura. No ano de 1995, a possível instalação desses empreendimentos e atividades econômicas, com a anuência dos órgãos públicos, provocou uma reação da população local que, por meio de entidades sociais representativas, mobilizou-se através de denúncias aos órgãos públicos competentes, como o Instituto Brasileiro de Meio Ambiente e Recursos Naturais Renováveis (IBAMA), Idema, Gerência Regional do Patrimônio da União (GRPU) e a imprensa. Além disso, esse movimento buscou o diálogo coma as instituições e apoio legal para promover a proteção do patrimônio natural e cultural do território.

Essa movimentação popular fortaleceu ainda mais a necessidade de se criar um instrumento legal que garantisse a proteção e preservação daquela área, "após a mobilização das comunidades [...] diversas reuniões foram realizadas para a elaboração do Decreto-lei, como proposição para criação e delimitação da reserva" (Nobre, 2005, p.99). Em 2003, o Conselho Estadual do Meio Ambiente do RN aprovou a proposta do Decreto-Lei e, no dia 18 de julho do mesmo ano, o Governo do Estado cria, por meio da Lei no 8.349, a Reserva de Desenvolvimento Sustentável estadual Ponta do Tubarão (Nobre 2005 apud OLIVEIRA, 2008, p. 56).

Em consonância com a normatização pré-estabelecida tanto no SNUC como no seu Decreto de regulamentação ( $n \div$ - 4.340/2002), o artigo $2^{\circ}$ da Lei no 8.349 estabelece como sendo o objetivo de criação da RDSEPT preservar a natureza e, ao mesmo tempo, assegurar as condições e os meios necessários para a reprodução e a melhoria dos modos e da qualidade de vida e exploração dos recursos naturais pelas populações 
tradicionais, bem como valorizar, conservar e aperfeiçoar o conhecimento e as técnicas de manejo do ambiente. $\mathrm{O}$ inciso $\mathrm{V}$, do artigo supracitado evidencia o fortalecimento e a organização comunitária, propiciando as condições para a gestão participativa e co-responsável dos bens ambientais (RN, Lei $n^{\circ}$ 8.349/2003).

\title{
A Lei 8.349/03 e o Conselho Gestor da RDSEPT: uma garantia de gestão participativa
}

O SNUC estabelece seus objetivos no artigo $4^{\circ}$ com medidas relacionadas à manutenção da diversidade biológica e dos recursos genéticos no território nacional e nas águas jurisdicionais; à proteção das espécies ameaçadas de extinção; à contribuição para a preservação e a restauração da diversidade de ecossistemas naturais; promoção do desenvolvimento sustentável; proteção de paisagens naturais; proteção das características relevantes de natureza geológica, geomorfológica, espeleológica, arqueológica, paleológica e cultural; proteção e recuperação dos recursos hídricos e edáficos; recuperação ou restauração de ecossistemas degradados; proporcionar meios e incentivos para atividades de pesquisa científica, estudos e monitoramento ambiental; favorecimento das condições e promoção da educação e interpretação ambiental, a recreação em contato com a natureza e o turismo ecológico; proteção dos recursos naturais necessários à subsistência de populações tradicionais, respeitando e valorizando seu conhecimento e sua cultura de modo que haja a promoção socioeconômica desta (BRASIL, 2000).

Como já foi dito anteriormente, o SNUC é a legislação que embasa a elaboração das leis estaduais e municipais relativas à criação, implantação e gestão de UCs. De acordo essa normativa superior, os objetivos propostos no artigo $4^{\circ}$ do parágrafo devem ser geridos através da formação de conselhos compostos por entidades paritárias e com interesse em gerir essas unidades. Com relação à RDS, o artigo 20 do SNUC diz o seguinte:

\begin{abstract}
A Reserva de Desenvolvimento Sustentável será gerida por um Conselho Deliberativo, presidido pelo órgão responsável por sua administração e constituído por representantes de órgãos públicos, de organizações da sociedade civil e das populações tradicionais residentes na área, conforme se dispuser em regulamento e no ato de criação da unidade (BRASIL, 2000)
\end{abstract}

Desse modo é possível perceber a visão estratégica que o SNUC propõe aos tomadores de decisão, de modo que possibilitem aos atores dessas unidades, além de preservarem os ecossistemas e a cultura local, gerar renda, emprego, oportunidade de trabalho e propiciar uma efetiva melhoria na qualidade de vida dessas populações. De acordo com Magalhães et al. (2010, p.184): 
O mecanismo de fortalecimento da gestão participativa previsto no SNUC é a formação dos Conselhos Gestores, com representação em sua composição, de $50 \%$ de organizações da sociedade civil, com caráter consultivo ou deliberativo.

A Lei 8.349/03 trata a formação do Conselho Gestor da RDSEPT em seus artigos $6^{\circ}$ a $8^{\circ}$, com embasamento na normativa do SNUC, instituindo esse colegiado como instância deliberativa e consultiva, com atribuições de elaborar o Regimento Interno e realizar o planejamento estratégico para a gestão da unidade. O CG da RDS foi instalado sendo composto por 19 (dezenove) membros, um titular e respectivo suplente que representam suas entidades conforme definido pela Lei de criação da Reserva:

Art. 6․ Fica constituído o Conselho Gestor da Reserva de Desenvolvimento Sustentável Estadual Ponta do Tubarão, como instância Deliberativa para o planejamento estratégico da unidade.

Art. $7^{\circ} . O$ presidente do Conselho Gestor da Reserva de Desenvolvimento Sustentável Estadual Ponta do Tubarãoe o seu suplente serão escolhidos, dentre os conselheiros componentes do Conselho, através de eleição.

Parágrafo Único: O Presidente do Conselho e seu Suplente serão eleitos por maioria simples dos votos dos seus membros.

Art. 8‥ Conselho Gestor da Reserva de Desenvolvimento Sustentável Estadual Ponta do Tubarão será composto por um membro titular e respectivo suplente representante de cada um dos seguintes órgãos e entidades:

I. Instituto de Desenvolvimento Econômico e Meio Ambiente do Rio Grande do Norte;

II. Instituto Brasileiro de Meio Ambiente e dos Recursos Naturais Renováveis e da Amazônia Legal;

III. Gerência Regional do Patrimônio da União;

IV. Poder Executivo do Município de Guamaré;

V. Poder Executivo do Município de Macau;

VI. Poder Legislativo do Município de Guamaré;

VII. Poder Legislativo do Município de Macau;

VIII. Representante do setor produtivo instalado na Reserva;

IX. Instituição de Ensino Superior, escolhida pela comunidade local, que desenvolva atividades de pesquisa na área da Reserva;

$X$. Representantes de dez entidades civis, sediadas nos municípios de Guamaré e Macau, que representem os interesses das populações tradicionais residentes na área de abrangência da Reserva. 


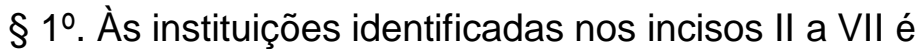
facilitada a indicação e a substituição dos membros, titulares e suplentes, que poderão representa-las no Conselho, competindo às demais instituições a indicação compulsória dos respectivos membros, titulares e suplentes.

$\S 2$. As entidades civis, representantes dos interesses das populações tradicionais, devidamente registradas em cartório, escolherão, mediante eleição efetuada em fórum específico para sua finalidade, os dez membros titulares e respectivos suplentes que representarão a comunidade local no Conselho (RN, LEI 8.349/2003).

Observa-se, pela análise dos documentos, a orientação legal que respalda a participação de vários representantes e grupos de interesses envolvidos em prol da Reserva, com o intuito de proteger os sistemas ecológicos e o patrimônio histórico-cultural local, está intrinsecamente alinhado aos objetivos de criação e gestão de unidades de conservação previstos no SNUC. Pelo que rege o artigo $2^{\circ}$ da $8.349 / 2003$, essa unidade tem como objetivo geral, a preservação dos recursos naturais e a sustentabilidade da população tradicional, a partir da garantia de condições e meios necessários para a reprodução, a melhoria dos modos e da qualidade de vida e exploração dos recursos naturais pelas populações tradicionais, valorizando e aperfeiçoando o conhecimento e as técnicas de manejo do ambiente desenvolvidos por estas comunidades.

De acordo com o IDEMA/RN (2007, p. 50):

A cidadania está presente no cotidiano, por meio do alto grau de sociabilidade e ações reivindicatórias observadas. As discussões são formais e acontecem nas associações comunitárias que se consolidam com a criação da Reserva.

Ainda comparando os dados coletados com a análise documental, os resultados corroboram com a visão de IRVING et al, 2006,p.86), que estabelece que,

O Conselho de UC deve se constituir, verdadeiramente, (...) um espaço de participação envolvendo liberdade de expressão, simetria e estratégias para remoção de barreiras ao discurso (questões de poder, ideológicas, conteúdos emocionais, ilusórios), no sentido de manifestação dos interesses individuais e coletivos.

Assim, evidencia-se na análise dos instrumentos de pesquisa, a existência de diretrizes norteadoras das políticas públicas que apóiam a participação social dos moradores na RDS Estadual Ponta do Tubarão. Assim, pelo disposto na Lei $\mathrm{n}^{\circ}$ 8.349/2003 que cria e implementa a RDS observa-se que esta apresenta certa acuidade no tocante ao alinhamento legal com Lei Complementar 272/04 e às previsões da Lei 9.985/00 
clarificando e garantindo as formas de participação na gestão da unidade pelo Conselho Gestor com vistas ao desenvolvimento comunitário local.

\section{Considerações finais}

Observa-se que os instrumentos normativos citados neste trabalho carecem de conceituação dos termos-chave utilizados na construção das normativas. A falta dessas definições pode ocasionar confusões conceituais e interpretativas ou até mesmo gerar conflitos no processo de tomada de decisões nas arenas de participação. A presença de populações humanas no interior das unidades de conservação é um marco diferencial para o estabelecimento dos processos de criação, implantação e gestão dessas áreas. Sendo a RDS Estadual Ponta do Tubarão uma unidade que permite a presença humana na ocupação desse espaço é preciso alertar para a complexidade socioambiental, econômica, política e cultural que essas comunidades representam e que devem ser cuidadosamente considerados na discussão e proposição de políticas públicas e instrumentos legais.

Analisando as normatizações da Lei Complementar 272/04 sobre as unidades de conservação do Rio Grande do Norte, constata-se que esta Lei se reporta às questões de definição, planejamento e gestão dessas áreas de forma superficial não definindo essas questões de maneira específica. Percebe-se que este dispositivo legal se serve do que é trazido pelo SNUC. Essa pode ser uma lacuna na legislação local que pode negligenciar questões socioambientais locais de relevante interesse da população na criação, implementação e gestão de unidades de conservação.

A participação da população residente e do entorno da área da unidade RDS Estadual Ponta do Tubarão pode ser considerada um diferencial no contexto da questão ambiental do $\mathrm{RN}$. Isso reflete que a sociedade contemporânea tem mostrado uma tendência crescente das pessoas em participar de arenas de tomadas de decisão acerca de suas vivências e um maior envolvimento e comprometimento com o meio ambiente. A garantia da gestão participativa em unidades de conservação tem sido uma conquista social que tem impulsionado o Poder Público, em todas as suas instâncias de governança, a atender essas reivindicações por meio de espaços de diálogo, conferências encontros e instrumentos legais como os evidenciados na temática deste trabalho.

Acredita-se que a participação e o potencial interesse da sociedade civil em participar pode ser uma consequência natural da evolução do pensamento social em relação à utilização dos recursos naturais de um modo mais racional, do respeito à pluralidade cultural e, não sendo isso possível, é importante que minimamente se recupere os prejuízos causados pela ação do homem. Espera-se que este trabalho contribua para que essa gestão participativa em áreas protegidas ocorra de forma qualificada e consciente de modo que os atores envolvidos e comprometidos com a criação, implementação de UC atentem para a necessidade de se pensar a realidade local na construção de instrumentos legais ${ }^{6}$. 


\section{Referências bibliográficas}

AVELAR, L. Participação Política. In: AVELAR, L.; CINTRA, A.C. Sistema político brasileiro: uma introdução. São Paulo: Editora Unesp, 2004.

BEZERRA, J. C. P. Direito e Etnoconservação: Estudo da Participação na gestão ambiental da RDS Estadual Ponta do Tubarão-RN. Dissertação de Mestrado, Universidade Federal do Rio Grande do Norte, Natal, RN, Brasil 2010.

BORDANEVE, J.E.D. O que é participação (8. Ed.). (Coleção Primeiros Passos). São Paulo: Brasiliense, 1994.

CARLSSON, L.; BERKES, F. Co-Management Across Levels of Organization: Concepts and Methodological Implications. Presented at "Politics of the Commons: Articulating Development and Strengthening Local Practices", Chiang Mai, Thailand, July 11-14, 2003. Disponível em:

$<$ http://dlc.dlib.indiana.edu/archive/00001133/00/Lars_Carlsson.pdf>.Acesso em 29/04/2015.

CONSTITUIÇÃO DA REPÚBLICA FEDERATIVA DO BRASIL DE 1988. (1988). Brasília. Acesso em 16 abril, 2014, de http://www.planalto.gov.br/ccivil 03/constituicao/constituicaocompilado.htm

COGO, E.L., DALLABRIDA, V.R. Descentralização e participação social: constatações e análises comparativas em experiências. Anais do Encontro da Associação Nacional de Pós-graduação e Pesquisa em Planejamento Urbano e Regional, Recife, PE, Brasil, 15, 2013.

DEMO, P. Participação é conquista. 5.ed. São Paulo: Cortez, 2001.

DIEGUES, A.C. A etnoconservação da natureza. In: DIEGUES, A.C. (Org.). Etnoconservação: novos rumos para a proteção da natureza nos trópicos. 2. ed. São Paulo: Hucitec e NUPAUB, p. 1-46, 2000.

IRVING, M.A. (org.) Áreas Protegidas e inclusão social: construindo novos significados. Rio de Janeiro: Fundação Bio-Rio: Núcleo de Produção Editorial Aquarius, 2006.

JACOBI, P. Poder local, políticas sociais e sustentabilidade. Saúde e Sociedade, Vol.8, n.1, 1999. Acesso em 20 abril, 2014, de http://www.scielo.br/pdf/sausoc/v8n1/04

LEI no 9.985 de 18 de julho de 2000 (2000). Regulamenta o art. 225, § 1o, incisos I, II, III e VII da Constituição Federal, institui o Sistema Nacional de Unidades de Conservação da Natureza. Brasília, DF. Acesso em 20 de abril, de 2014, de http://www.planalto.gov.br/ccivil 03/leis/19985.htm

DECLARAÇÃO DO RIO SOBRE MEIO AMBIENTE E DESENVOLVIMENTO. Acesso em 16 abril, 2014, de http://www.onu.org.br/rio20/img/2012/01/rio92.pdf.

LEI COMPLEMENTAR o 272 de 3 de março de 2004 (2004). Dispõe sobre a Política e o Sistema Estadual do Meio Ambiente do Rio Grande do Norte. Natal, RN. Recuperado em 16 de abril, 2014, de http://adcon.rn.gov.br/ACERVO/idema/DOC/DOC000000000004021.PDF 
LEI no 8.349 de 18 de julho de 2003. Cria a Reserva de Desenvolvimento Sustentável Estadual Ponta do Tubarão, na região de Diogo Lopes e Barreiras nos Municípios de Macau e Guamaré no Rio Grande do Norte. Natal, RN.

\section{LOUREIRO, C.B. et al Educação ambiental e gestão participativa em} unidades de conservação. Rio de Janeiro: Ibase e lbama, 2003.

MACEDO, S.H. Processos participativos na gestão de Unidades de Conservação. In: SEMINÁRIO NACIONAL MOVIMENTOS SOCIAIS, PARTICIPAÇÃO E DEMOCRACIA, 2. , 2007, Florianópolis, SC. Anais... Florianópolis: Núcleo de Pesquisa em Movimentos Sociais 2007. Disponível em: HTTP://www.sociologia.ufsc.br/npms/heitor schulz macedo.pdf. Acesso em: 29/04/2015.

GOHN, M.G. Conselhos gestores e participação sociopolítica. 3 ed. São Paulo: Cortez, 2007.

MAGALHÃES, H., BONONI V. L. R., Mercante M. A. Participação da sociedade civil na gestão de unidades de conservação e seus efeitos na melhoria da qualidade ambiental da região Sudeste do Estado do Mato Grosso do Sul. Dissertação de

MAGALHÃES, H.; BONONI, V. L. R.; MERCANTE, M. A. Participação da sociedade civil na gestão de unidades de conservação e seus efeitos na melhoria da qualidade ambiental da região Sudeste do Estado do Mato Grosso do Sul. Acta Scientiarum. Human and Social Sciences, Maringá, v. $32, \quad$ n. 2, p. 183-192, 2010. Disponível em: http://periodicos.uem.br/ojs/index.php/ActaSciHumanSocSci/article/viewFile/ $\underline{6761 / 6761}$. Acessado em 24/08/2015.

\section{Notas:}

1 Espaço territorial e seus recursos ambientais, incluindo as águas jurisdicionais, com características naturais relevantes, legalmente instituído pelo Poder Público, com objetivos de conservação e limites definidos, sob regime especial de administração, ao qual se aplicam garantias adequadas de proteção (BRASIL, 2000).

2 É um lugar onde a sociedade pode participar efetivamente para a prevenção de problemas e soluções das questões socioambientais da região da Unidade (BRASIL, 2007).

${ }^{3}$ Documento técnico mediante o qual, com fundamento nos objetivos gerais de uma unidade de conservação, se estabelece o seu zoneamento e as normas que devem presidir o uso da área e o manejo dos recursos naturais, inclusive a implantação das estruturas físicas necessárias à gestão da unidade (BRASIL, 2000).

4 São diretrizes e princípios norteadores de ação do poder público; regras e procedimentos para as relações entre poder público e sociedade, mediações entre atores da sociedade e do Estado. São, nesse caso, políticas explicitadas, sistematizadas ou formuladas em documentos (Leis, programas, linhas de financiamentos) que orientam ações que normalmente envolvem aplicações de recursos públicos (TEIXEIRA, 2002, p. 2). 
${ }^{5}$ Segundo interpretação do artigo $17, \S 2^{\circ}$ desta Lei, dada por Machado (2002, p. 225).

${ }^{6}$ Este trabalho teve o apoio financeiro da CAPES

Iracy Wanderley-Filha: Universidade Federal do Rio Grande do Norte, Natal, RN, Brasil.

E-mail: cici.w@gmail.com.

Link para o currículo Lattes: http://lattes.cnpq.br/5372082985640197

Maria Valéria Pereira de Araújo: Universidade Federal do Rio Grande do Norte, Natal, RN, Brasil.

E-mail: valeriaraujoufrn@gmail.com.

Link para o currículo Lattes: http://lattes.cnpq.br/9227834040889428

Sonia Trigueiro de Almeida: Universidade Potiguar, Natal, RN, Brasil.

E-mail: drasoniatrigueiro@gmail.com.

Link para o currículo Lattes: http://lattes.cnpq.br/9995963434860331

Data de submissão: 31 de outubro de 2014

Data de recebimento de correções: 21 de maio de 2015

Data do aceite: 21 de maio de 2015

Avaliado anonimamente 